\title{
Considerations and Controversies of AIDS Medard Kounionguina*‡
}

\author{
Address: L'Association Soliderite Sainte, Congo \\ Email: Medard Kounionguina* - medard_kounionguina@yahoo.fr \\ * Corresponding author $\ddagger$ Presenting author
}

from 2005 International Meeting of The Institute of Human Virology

Baltimore, USA, 29 August - 2 September 2005

Published: 8 December 2005

Retrovirology 2005, 2(Suppl I):P5I doi: I0.I I86/I742-4690-2-SI-P5 I

The statistical probability of seroconversion is proportional to the number of needlesticks incurred and the likelihood that the needlesticks will be with HIV infected blood. Careful adherence to recommended operating room practices, combined with meticulous attention to handling needles and sharps, should result in few, if any, cases of occupational HIV seroconversion among OR personnel. HIV testing is not feasible in the management of emergency patients; these are often the individuals at highest risk for HIV infection and over whom the surgical team has the least control. Non-operative treatment of HIV-infected patients is not an option; many procedures are performed either to enable the individual to lead a more comfortable, productive life or for diagnostic purposes. 